\title{
Redlich-Kwong 状態式による高圧気液平衡の推算*
}

\author{
賴 実 正 弘**, 舛 岡 弘勝** \\ Prediction of High Pressure Vapor-Liquid Equilibria from \\ the Redlich-Kwong Equation of State* \\ by Masahiro Yorizane** and Hirokatsu Masuoka**
}

\begin{abstract}
Summary : This paper presents a method for predicting the vapor-liquid equilibria at high pressures from the modified Redlich-Kwong equations of state. The binary interaction constants in the vapor and liquid phase were determined from several binary vapor-liquid equilibrium data. The binary interaction constants in vapor phase were in good agreement with those determined from $p V T$ data by Chueh and Prausnitz. Though the binary interaction constants in the liquid phase did not check with those determined from the saturated liquid molar volume by Chueh and Prausnitz, a correlation of interaction constants with the critical molar volume was obtained.
\end{abstract}

\section{1 緒言}

Redlich-Kwong 状態式"14) (RK 式と呼ぶことにする) は現 在までに発表されている二定数の状態式の中でもっとも精度が よく，特に臨界点付近の傾向が八定数の BWR 状態式よりもよ い場合があるといわれている゙”。Martin" および Shar と $\operatorname{Thodos}^{17)}$ は RK 式より精度のよい二定数の式を作ろうと試 みたがいずれも不成功に終っている。しかし，液相の $p V T$ 関 係を精度よく表わすには，RK 式は精度が悪いので Redlich らは二定数のほかに 41 個の定数を導入した として Chueh と Prausnitzは, 気液两相に対して新たに物質 固有の定数を導入した RK 式を使用し, 気相のフガシチ你数 ${ }^{31}$, 液相の飽和分子容 (または偏分子容 $)^{1)}$ の実駼值に合うように 気相㧍よび液相の二成分相互作用定数を求めた。佊らは偏分子 容を算出する際, 偏分子容の式中の飽和分子容には, 混合物の 対応状態相関による䅳和液体分子容を用いている（温度と組成 が与えられると，原理的には，RK 式から液体混合物の飽和分 子容を推算することができるわけであるが，液相における精度 が十分でないために上のような手法を用いたのである)。RK式 は,従来高圧気液平衡の推算に使用されてきた BWR の状態式 と比較して，精度の点でやや劣るという久点もあるが，式が節 単なため計算が容易といら利点がある。本論文では，混合物の 対応状態相関による飽和液体分子容と RK 式を用いて, 液相 のフガシチ係数を算出し，これを用いて高圧気液平衡を推算す る方法について述べ，数組の二成分系の推算を行ない，その適 用性について検㮘した。

\section{2 推 算 法}

高圧における気液平衡は気液比を用いて表わされる。i成分

* 昭和 44 年 2 月 8 日受理

**広島大学工学部 (広島市千田町 3丁目) Faqf ty of Engineering, Hieroshima University (3-chome, Sendamachi, Hiroshima)
の気液比は,

$$
K_{i}=y_{i} / x_{i}
$$

で定義される。気相と液相が平衡のとき， $i$ 成分の両相のフガ シチが等しいことから，

$$
K_{i}=\frac{\bar{f}_{i}^{L} / x_{i} p}{\bar{f}_{i}^{V} / y_{i} p}=\frac{\varphi^{L}}{\varphi^{V}}
$$

となり，気液比は気液両相のフガシチ係数で表わすことができ る。フガシチ倸数は次式で計算される。

$$
\ln \frac{\bar{f}_{i}}{y_{i} p}=\ln \frac{\rho R T}{p}+\int_{0}^{\rho}\left[\left(\frac{\partial p V}{\partial n_{i}}\right)_{n_{j, V}, T}-R T\right] \frac{d \ln \rho}{R T}
$$

RK 式は次式で与えられる。

$$
p=\frac{R T}{v-b}-\frac{a}{T^{0.5} v(v+b)}
$$

フガシチ倸数は式 (3),(4) より，

$$
\begin{aligned}
\ln \varphi_{k} v & =\ln \frac{v}{v-b}+\frac{b_{k}}{v-b}-\frac{2 \sum_{i} y_{i} a_{i k}}{R T^{3 / 2} b} \ln \frac{v+b}{v} \\
& -\frac{a b_{k}}{R T^{3 / 2} b^{2}}\left[\ln \frac{v+b}{v}-\frac{b}{v+b}\right]-\ln \frac{p v}{R T}
\end{aligned}
$$

ここで定数 $a, b$ は, Chueh ら ${ }^{3)}$ によりつぎのように与えら れている。

$$
\begin{aligned}
& a=\sum_{i} \sum_{j} y_{i} y_{j} a_{i i}{ }^{V}, a_{i i}{ }^{V}=Q_{a i}{ }^{V} R^{2} T_{c i}{ }^{2.5} / p_{c i} \\
& a_{i j}{ }^{V}=\frac{\left(Q_{a i}{ }^{V}+\Omega_{a j}{ }^{V}\right) R T_{c i j}{ }^{1.5}\left(v_{c i}{ }^{1 / 3}+v_{c j} j^{1 / 3}\right)^{3}}{16\left\{0.291-0.04\left(\omega_{i}+\omega_{j}\right)\right\}} \\
& \therefore b^{V}=\sum_{i} y_{i} b_{i}{ }^{V}, \quad b_{i}{ }^{V}=\ell_{b i}{ }^{V} R T_{c i} / p_{c i} \\
& T_{c i j}=\sqrt{T_{c i} T_{c j}}\left(1-k_{i j}{ }^{V}\right)
\end{aligned}
$$




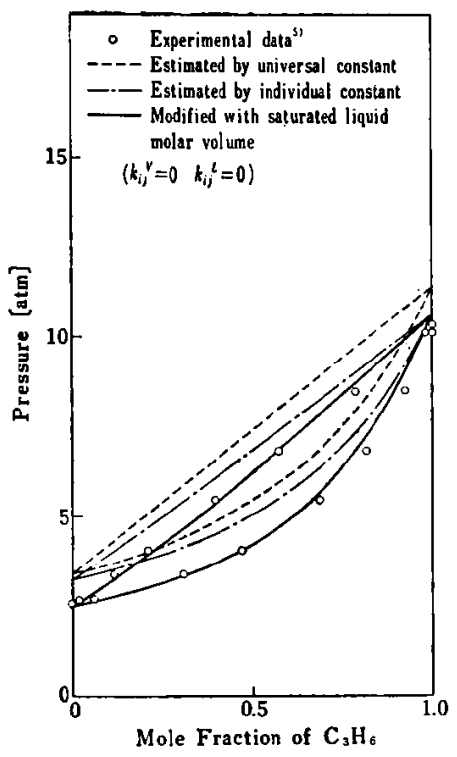

Fig. $1 \mathrm{C}_{8} \mathrm{H}_{6}-\mathrm{I}-\mathrm{C}_{6} \mathrm{H}_{6}$ System $\left(294.26^{\circ} \mathrm{K}\right)$

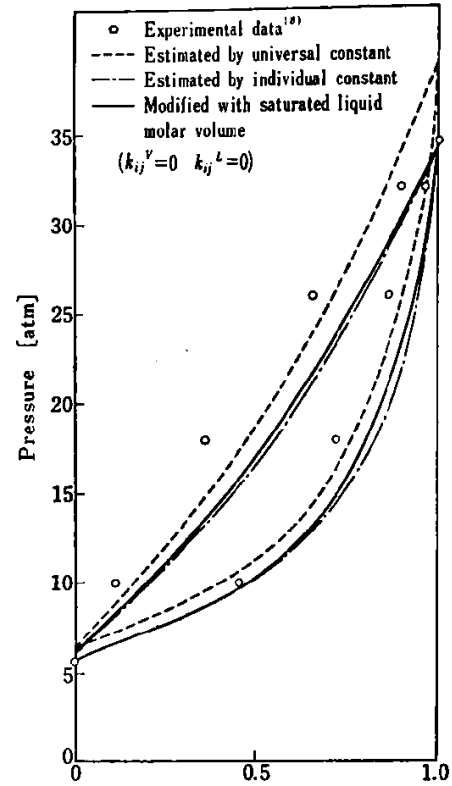

Mole Fraction of $\mathrm{CO}_{2}$

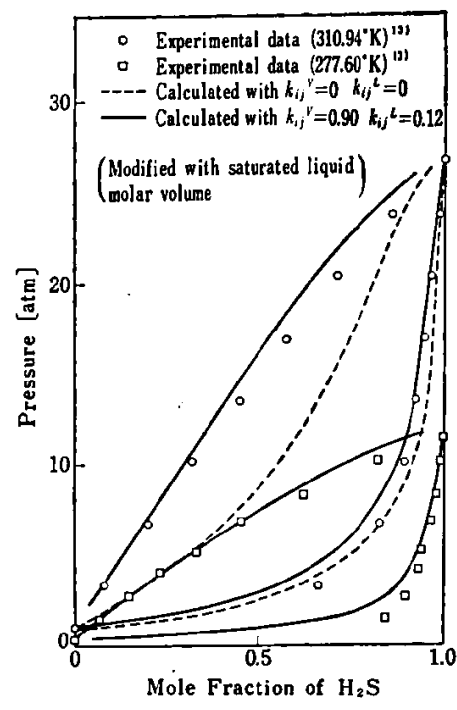

Fig. $3 \mathrm{H}_{2} \mathrm{~S}-n-\mathrm{C}_{8} \mathrm{H}_{t 2}$ System

Fig. $2 \quad \mathrm{CO}_{2}-\mathrm{C}_{8} \mathrm{H}_{6}$ System $\left(273.16^{\circ} \mathrm{K}\right)$

るとすると，式 (5) 方成立する。式 (6) において $y$ は $x$ に, 添字 $V$ は $L$ に変えた液相の值に固き換えられる。たたし,

$$
a_{i j}{ }^{L}=\frac{\left(Q_{a i}{ }^{L}+Q_{a j}{ }^{L}\right) R T_{c i j}{ }^{1.5}\left(v_{c i}+v_{c j}\right)}{4\left\{0.291-0.04\left(\omega_{i}+\omega_{j}\right)\right\}}
$$

$\ell_{a i}{ }^{L}, \Omega_{b i}{ }^{L}$ の值は純粋成分の的和液体の $p V T$ に合うように 決められている1。 このようにして気相と液相のフガシチ伱数 が求まると最も広く行なわれている BWR 状態式による高圧 気液平衡の推算法と同し手法で式 (2) を用いて気液比を推算す ることができる。

上述の方法で $\mathrm{C}_{3} \mathrm{H}_{6}-1-\mathrm{C}_{4} \mathrm{H}_{6}$ 系, $\mathrm{CO}_{2}-\mathrm{C}_{3} \mathrm{H}_{6}$ 系について推算 した結果を Fig. 1, 2 に一点鎖線で示す。点線は $\Omega_{a}, \Omega_{b}$ の值 に気液相とも，それぞれ $0.4278 ， 0.0867$ (臨界点の条件から決 まる值）を使用した場合を示す。物缺固有の $\boldsymbol{g}_{a}, \boldsymbol{\Omega}_{b}$ の值を使用したほうが夷測值に近いことがわかる。他 の系にっけても同様の傾向があった。これは特に RK 式による液相の $p V T$ の精度が悪いためと考えられ る。それで，与えられた組成，温度，压力において RK 式から分子容が決まるわけであるが，式(5)に対 応する液相のフガシチ倸数の式中で，この分子容を用 いずに他の推算法からの分子容を導入することを試み た。この的和液体分子容の推算には, 以下に述べる Lyckman ら"の対応状態相関を使用した。

$0.56<T_{R}<0.93$ のときは，

$$
\begin{aligned}
v_{R} & =v / v_{c M}=v_{R}^{(j)}+\omega_{M} v_{R^{(1)}}+\omega_{M} v_{R} v^{(2)} \\
v_{R}^{(j)} & =a^{(j)}+b^{(j)} T_{R}+c^{(j)} T_{R^{2}}+d^{(j)} T_{R} \\
& +e^{(j)} / T_{R}+f^{(j)} \ln \left(1-T_{R}\right)
\end{aligned}
$$

$a^{(j)}, b^{(j)}, \cdots f^{(j)}$ の数值は文献 1)にある。また，仮 臨界容皘, 仮臨界温度, 混合物の偏心係数は, 以下の ように与えられている。

$$
\begin{aligned}
& v_{c M}=\sum_{i} x_{i} v_{c i} \\
& T_{c M}=\sum_{i} \sum_{j} \emptyset_{i} \Phi_{j} T_{c i j}
\end{aligned}
$$

$$
\begin{aligned}
T_{c i j} & =\sqrt{T_{c i} T_{c j}}\left(1-k_{i j}{ }^{L}\right) \\
\omega_{M} & =\sum_{i} \Phi_{i} \omega_{i} \\
\emptyset_{i} & =x_{i} v_{c i} / \sum_{k} x_{k} v_{c k}
\end{aligned}
$$

臨界城 $\left(0.93<T_{R}<1\right)$ の場合には，つぎの修正臨界值を用い る。

$$
\begin{aligned}
T_{c M^{\prime}} & =T_{c M}+\left(T_{c T}-T_{c M}\right) \mathscr{D}\left(T_{R}\right) \\
v_{c M^{\prime}} & =v_{c M}+\left(v_{c T}-v_{c M}\right) \mathscr{D}\left(T_{R}\right) \\
こ こ て ゙, & \\
\mathscr{D}\left(T_{R}\right) & =\exp \left[( T _ { R } - 1 ) \left(2901.01-5738.92 T_{R}\right.\right. \\
& \left.\left.+2849.85 T_{R}{ }^{2}+\frac{1.74127}{1.01-T_{R}}\right)\right]
\end{aligned}
$$
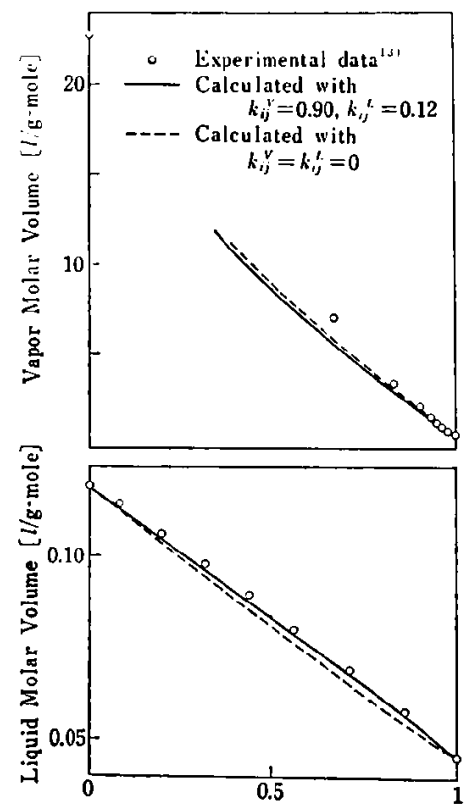

Mole Fraction of $\mathrm{H}_{2} \mathrm{~S}$

Fig. 4 Saturated Molar Volume of $\mathrm{H}_{2} \mathrm{~S}-n-\mathrm{C}_{3} \mathrm{H}_{12}$ System $\left(310.94^{\circ} \mathrm{K}\right)$ ( 30 )

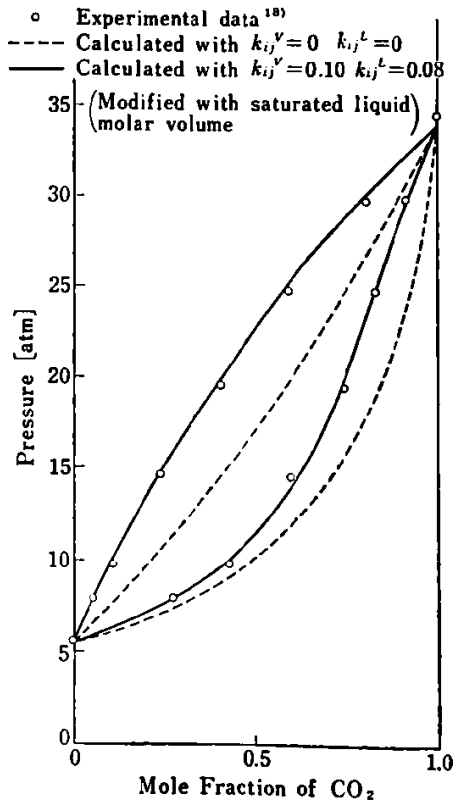

Fig. $5 \mathrm{CO}_{2}-\mathrm{C}_{2} \mathrm{H}_{6}$ System $\left(273.16^{\circ} \mathrm{K}\right)$ 


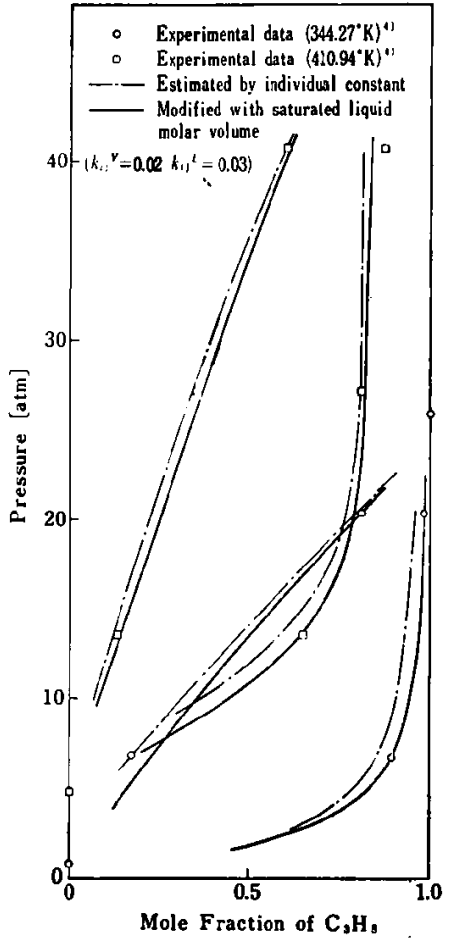

Fig. $6 \mathrm{C}_{3} \mathrm{H}_{6}-\mathrm{C}_{3} \mathrm{H}_{0}$ System

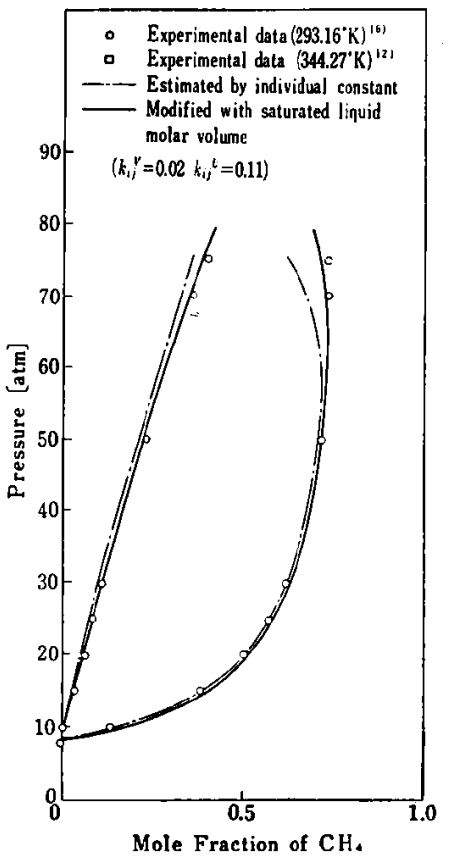

Fig. $7 \mathrm{CH}_{4}-\mathrm{C}_{2} \mathrm{H}_{3}$ System $\left(293.16^{\circ} \mathrm{K}\right)$

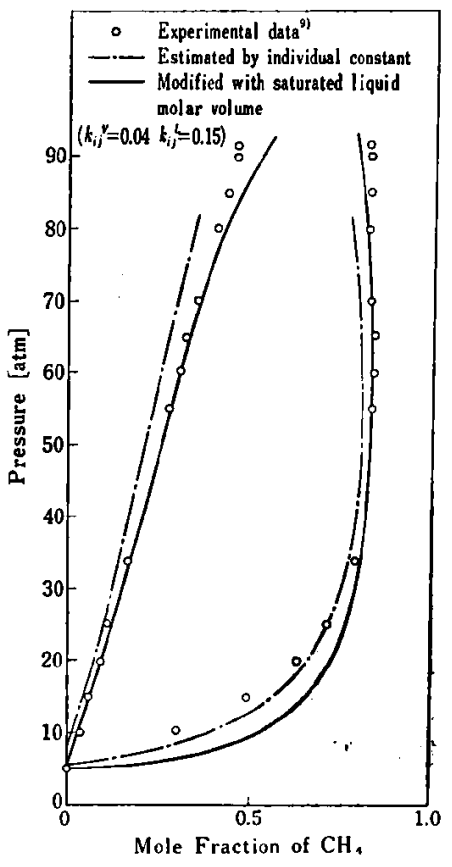

Fig. $8 \mathrm{CH}_{4}-i-\mathrm{C}_{4} \mathrm{H}_{10}$ System $\left(310.94^{\circ} \mathrm{K}\right)$

$$
\begin{aligned}
T_{c T} & =\theta_{1} T_{c 1}+2 \theta_{1} \theta_{2} \tau_{12}+\theta_{2} T_{c 2} \\
v_{c T} & =\theta_{1} v_{c 1}+2 \theta_{2} \theta_{2} \nu_{12}+\theta_{2} v_{c 2} \\
\theta_{i} & =x_{i} v_{c i} i^{2 / 3} / \sum_{h} x_{k} v_{c k}{ }^{2 / 9}
\end{aligned}
$$

$\tau_{12}, \nu_{12}$ は二成分定数で文献にある。

\section{3 結果および考察}

上記の分子容を用いた推算結果を Fig. 1，2 に実線で示す。 Fig. 1 では実測值との一致が良好であることがわかる。Fig. 2 ではあまり影需がない。他の系についても分子容を使用した 結果のほらが分子容を使用しない結果よりもよかった。

Fig. 3 に $\mathrm{H}_{2} \mathrm{~S}-n-\mathrm{C}_{5} \mathrm{H}_{12}$ 系の結果を示す。この場合には,

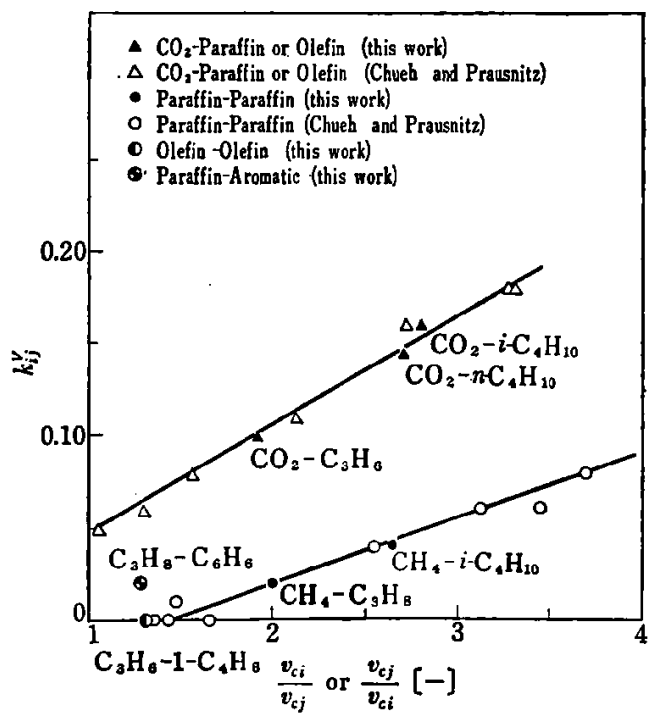

Fig. 9 Variation of $k_{l j}{ }^{\nabla}$ with Critical Volume Ratio $k_{i j}$ を導入しなければ推算結果はよくならない。実測値に合う ように決めた $k_{i j}$ による結果を実線で示す。このときの分子容 の変化を示したのが Fig. 4 である。310.94K のデータに注 目すると, Fig. 3 では $k_{i j}$ の変化により気液平衡が大きく変 化したが，Fig. 4 の分子容は気夜両相とも変化が少ない。換 言すれば，分子容のわずかの変化が気液平衡に大きく影響する ことがわかる。このようなことから混合物の分子容，特に液相 の分子容を精度よく表わすことが気液平衡の推算の一つの条件 になると考えられる。

Fig. 5 に $\mathrm{CO}_{2}-\mathrm{C}_{3} \mathrm{H}_{6}$ 系の推算結果を示寸。二成分定数を導 入しなければ精度が悪いが，Chueh らの報告している二成分

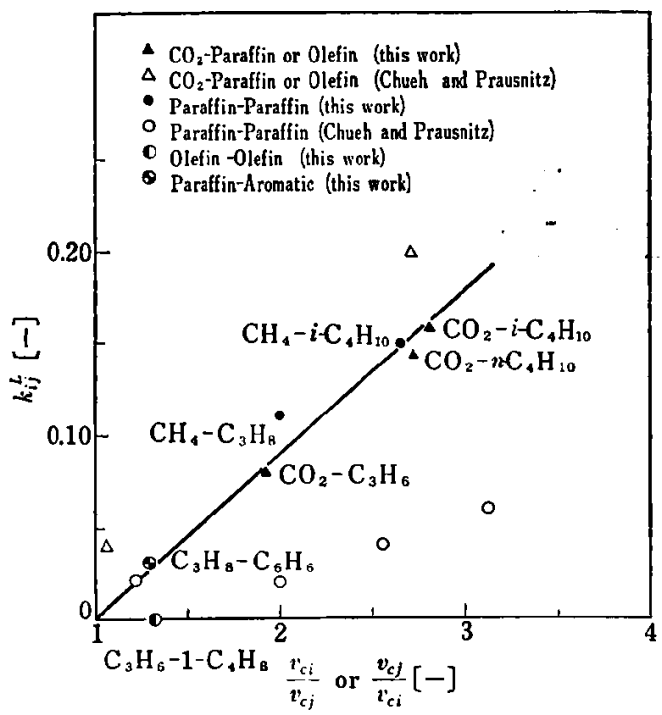

Fig. 10 Variation of $k_{i j}{ }^{L}$ with Critical Volume Ratio 
定数の值を用いると推算がよくなる。当然のことではあるが， $k_{i j}{ }^{V}$ は気相に, $k_{i j}{ }^{L}$ は液相により大きく影響する。Fig. 6, 7,8 に臨界域近くの推算結果を示す。

気液平衡に合うように決めた $k_{i j}{ }^{V}, k_{i j}{ }^{L}$ を臨界容積の比に 対してプロットすると,Fig.9, 10 のようになる。 $k_{i j} v$ は $\mathrm{CO}_{2}-$ パラフィンまたはオレフィン系と,パラフィンーパラフィン系の 2 本の線で表わすことができる。両図とも，Chueh らが気相， 液相のデータから求めた值を亚記している。気相は彼らが p VT のデータから決めた值と一致している。液相は彼らが飽 和液体分子容のデータから決めた值とかなりのずれがあるが， 気液平衡の場合には 1 本の線で表わすことができる。ただし， $\mathrm{H}_{2} \mathrm{~S}-n-\mathrm{C}_{5} \mathrm{H}_{12}$ 系の $k_{i j}$ は，相関から大きくはずれた。

\section{4 結 論}

Chueh と Prausnitzによって修正された Redlich-Kwong 状 態式を用いて高圧気液平衡を推算した。気相と液相の二成分相 互作用定数を気液平衡の実測值に合うように決めた。気相の 相互作用定数は気相の $p V T$ データからの定数上一致した。 液相の定数は Chueh らが飽和液体分子容のデータから決めた 值と一致しなかったが，臨界分子容とある程度の相関を得た。

$a:$ Redlich-Kwong 定数 $\left[\mathrm{atm}\left({ }^{\circ} \mathrm{K}\right)^{0.5} /(l / \mathrm{g}-\text { mole })^{2}\right]$
$b:$ Redlich-Kwong 定数 $[l / \mathrm{g}-\mathrm{mole}]$
$f:$ フガシチ $[\mathrm{atm}]$
$k:$ 二成分相互作用定数 $[-]$
$n:$ モル数 $[\mathrm{g}-\mathrm{mole}]$
$-p:$ 圧 カ $[\mathrm{atm}]$
$R:$ 気体定数 $\left[(l / \mathrm{g}-\mathrm{mole})(\mathrm{atm}) /\left({ }^{\circ} \mathrm{K}\right)\right]$
$T:$ 絶対温度 $\left[{ }^{\circ} \mathrm{K}\right]$
$v:$ 分子容 $[l / \mathrm{g}-\mathrm{mole}]$
$V:$ 全容積 $[l]$
$x:$ 液相のモル分率 $[-]$
$y:$ 気相のモル分率 $[-]$
$\theta:$ 表面分率 $[$ 一 $]$

$\rho:$ 密 度 $[\mathrm{g}-\mathrm{mole} / \mathrm{l}]$

$\varphi:$ フガシチ係数 $[$ 一]

$\Phi:$ 容積分率 $[$ - ]

$\Omega$ : Redlich-Kwong 定数

$\omega:$ 偏心係数 $[$ - ]

上付記号

一: 偏分子量 $L:$ 液体 $V:$ 蒸気

下付記号

$$
\begin{aligned}
& c \text { : 臨界值 } i, j, k: \text { 成分 } i, j, k \quad M \text { : 混合物 } \quad R: \text { 逯 } \\
& \text { 元値 } T: \text { 実験值 } \\
& \text { 引用文献 }
\end{aligned}
$$

1) Chueh, P.L., Prausnitz, J.M., A.I.Ch.E. Journal, 13, 1099 (1967).

2) Chueh, P.L., Prausnitz, J.M., ibid., 13, 1107 (1967).

3) Chueh, P.L., Prausnitz, J.M., Ind. Eng. Chem., Funda. mentals, 6, 492 (1967).

4) Glanville, J.W. et al., Ind. Eng. Chem., 12, 508 (1950).

5) Goff, G.H., Farrington, P.S., Sage, B.H., ibid., 42, 735 (1950).

6) Kay, W.B., ibid., 33, 590 (1941).

7) Lyckman, E.W., Eckert, C.A., Prausnitz, J.M., Chem. Eng. Sci., 20, 685 (1965).

8) Martin, J.J., Ind. Eng. Chem., 59, (12), 35 (1967).

9) Olds, R.H., Sage, B.H., Lacey, W.N., ibid., 34, 1008 (1942)

10) Poettmann, F.H., Katz, D.L., ibid., 37, 847 (1945).

11) Prausnitz, J.M., Gunn, R.D., A.I.Ch.E. Journal, 4, 430 (1958).

12) Reamer, H.H., Sage, B.H., Lacey, W.N., Ind. Eng. Chem., 42, 534 (1950).

13) Reamer, H.H., Sage, B.H., Lacey, W.N., ibid., 43, 976 (1951).

14) Redlich, O., Kwong, J.N.S., Chem. Rev., 44, 233 (1949)

15) Redlich, O., Ackerman, F.J., Gunn, R.D., Jacobson, M., Lau, S., Ind. Eng. Chem., Fundamentals, 4, 369 (1965)

16) Sage, B.H., Lacey, W.N., Schaafsma, J.G., Ind. Eng. Chem., 26, 214 (1934).

17) Shah, K.K., Thodos, G., ibid., 57, (3), 30 (1965).

18）赖実正弘, 吉村尚真, 年岡弘勝, 化学工学, 30, 1093 (1966).

19）頼实正弘，吉村尚页，堌田弘昭，化学工学第 32 年会硬演要旨集, 102 (1967).

20) 頼実正弘, 舛岡弘勝, 石油誌, 12, (1), 14 (1969).

\section{国内ニュース}

今期業界, 前年同期下回りそう石油 8 社 (日本石油, 昭和石油, 丸善石油, 三菱石油, 興严石油, 東亜石油, ゼネ ラル石油, 出光興産) の3 月期決算が 13 日, 出そろった。 それによると，石油製品市況の不振が響き，各社の業績はさ えなかったが, 日本石油, 昭和石油, 出光興産のように経営 利益が前年同期を上回る会社もあり，当初予想されたほどの 業績の落ち込みはなかた。今9月期は不需要期のらえ, 市 沉の回復は期待薄で前年同期を下回る業續になる可能性が強
い。この中で, 昭和石油は業績の落ち込みが避けられれば今 期に 8 期ぶりに復配したい考えである。石油製品の市況は喛 冬異変や各社の増設による供給過剩の表面化などでこの期中 低迷した。需要期に伴う販売数量の伸びに比べて売り上げの 伸びが鈍いのはこのためである。しかし(1)昨年 3 月期にスエ ズ動乱の余波で高滕したタンカーレートがこの期汢落ち着い た，(2)設储の合理化による製造コストの低下，(3流通経費の 合理化，(4)重油の選別販売に努力した，(5)原油を安く手当で きた、—などで市沇の悪化をある程度補うことができた。 